\title{
IDEAÇÃO DE PRODUTOS E SERVIÇOS NA PERSPECTIVA DA INOVAÇÃO: PROPOSTAS PARA AMMBIENTES ESCOLARES
}

http://dx.doi.org/10.5902/2318133835707

\author{
Adriane Terezinha Filipetto ${ }^{1}$ \\ Ana Paula de Almeida ${ }^{2}$ \\ Marcos José Andrighetto ${ }^{3}$ \\ Tiago Saidelles ${ }^{4}$ \\ Claudemir de Quadros 5
}

\begin{abstract}
Resumo
Neste texto apresentam-se resultados de atividade desenvolvida na disciplina Gestão Escolar e Inovação, vinculada ao Programa de Pós-Graduação em Educação Profissional e Tecnológica do Colégio Técnico Industrial de Santa Maria. A partir do conteúdo das aulas foram estudadas as relações entre gestão escolar e inovação, com vistas à ideação de um produto ou serviço que possa auxiliar na melhoria do desempenho de escolas. Assim, foram apresentadas quatro propostas: Plataforma de apoio à formatação de textos acadêmicos da UFSM de acordo com o Manual de dissertações e teses; Mapas mentais: ferramenta de apoio a aprendizagem; Full-Time Trajectory: uma ferramenta auxiliar de gestão educacional para acompanhar a trajetória formativa de estudantes na contemporaneidade e Ferramenta de ensino e aprendizagem baseada no conceito de gamificação. Pela ideação foram identificados e abordados problemas, estimulado o desenvolvimento de um pensamento criativo, assim como logrou-se tornar as aulas mais engajadoras e estimulantes para os estudantes no seu processo de ensino e aprendizado.
\end{abstract}

Palavras-chave: escola; gestão escolar; inovação.

\section{IDEATION OF PRODUCTS AND SERVICES FROM THE VIEWPOINT OF INNOVATION: PROPOSALS TO SCHOOL ENVIRONMENTS}

\section{Abstract}

In this text are presented results of the activity developed in a course of School Management and Innovation, associated to Postgraduate Program in Professional and Technological Education, at Technical Industrial College, in Santa Maria. From the class's content, the relationship between scholar management and innovation were studied, in order to the ideation of a product or service that can support the improvement of schools' performances. Thus, four proposals were presented: a Platform to support academic text formatting at UFSM according to Thesis and Dissertation Manual; Mind Maps: learning support tool; Full-Time Trajectory: an auxiliary tool of educational

${ }_{1}^{1}$ Colégio Técnico Industrial de Santa Maria, Brasil. E-mail: atfilipetto@yahoo.com.br.

2 Instituto Federal de Educação, Ciência e Tecnologia do Rio Grande do Sul, campus de Ibirubá, Brasil. Email: ana.almeida@ibiruba.ifrs.edu.br.

3 Instituto Federal de Educação, Ciência e Tecnologia Farroupilha, campus de Santo Augusto. E-mail: marcos.andrighetto@iffarroupilha.edu.br.

${ }^{4}$ Colégio Técnico Industrial de Santa Maria, Brasil. E-mail: tiago-saidelles@redes.ufsm.br.

${ }^{5}$ Universidade Federal de Santa Maria, Brasil. E-mail: claudemirdequadros@gmail.com.
Regae: Rev. Gest. Aval. Educ.
Santa Maria
v. 8
n. 17
Pub. contínua 2019
p. $1-15$ 
management to follow up formative trajectory of students in the contemporaneity and Teaching and learning tool based on the gamification concept. Through the ideation were identified and approached issues, encouraged the development of creative thought, as well as it was achieved to devolve classes into engagers and motivational ones, to students in its teaching and learning process.

Key-words: school; scholar management; innovation. 


\section{Introdução}

a perspectiva de Navarro (2000) a inovação numa instituição escolar se

N relaciona-se com mudança, com algo novo e tem como intenção melhorar alguma coisa. É justificada pela possibilidade de proporcionar melhor desempenho ou resultado do estudante ou, em outras palavras, mais e melhor aprendizagem. Envolve ação de inovar, conteúdo da inovação e resultado da inovação, assim como requer atuação intencional, ou seja, busca influenciar, mudar atitudes, persuadir. Neste sentido, o ator da inovação é o professor.

Em termos gerais a inovação relaciona-se com eficácia ou resultados; eficiência ou custos e processos internos. Pode ser induzida externamente ou gerada internamente, envolve difusão, comunicação e adoção, pode ser organizacional ou didática e envolve uma série de componentes: operações para manutenção dos limites, tamanho e extensão, instalações, tempo escolar, objetivos instrutivos e formativos, procedimentos, definição de papéis, valores, relações entre as partes, socialização, conexão entre sistemas. Pode ser relacionar, ainda, com diferentes modos, intensidades e amplitudes.

Para Navarro (2000), um importante argumento para a inovação seria que

la instituición escolar necessita acomodarse a una doble presión: desde el exterior se exige más de las esculas, al tempo que se interior se hace mas problemático y conflictivo. Por otra parte, las escuelas reclaman más autonomia, más recursos, más apoyo. Los professores demandan una mejor preparación inicial y continua, para afrontar com eficacia las nuevas circunstancias y ejercer su rol profesional de un modo más satisfactorio y estimulante. (p. 18)

A partir desta referência iniciou-se um trabalho na disciplina Gestão Escolar e Inovação, vinculada ao Programa de Pós-Graduação em Educação Profissional e Tecnológica do Colégio Técnico Industrial de Santa Maria, a partir do qual cabia aos estudantes pensar e propor um produto, serviço ou metodologia de trabalho que possa auxiliar na melhoria do desempenho de escolas. Neste texto destacam quatro propostas apresentadas: Plataforma de apoio à formatação de textos acadêmicos da UFSM de acordo com o Manual de dissertações e teses; Mapas mentais: uma ferramenta de apoio a aprendizagem; Full-Time Trajectory: uma ferramenta auxiliar de gestão educacional para acompanhar a trajetória formativa do educando na contemporaneidade e Implementação de uma ferramenta de ensino e aprendizagem baseada no conceito de gamificação.

\section{Plataforma de apoio à formatação de textos acadêmicos da UFSM de acordo com o MDT}

Adriane Terezinha Filipetto

Todos os dias e em todos os lugares somos apresentados a inovações de vários tipos, seja na área da educação, no lazer, na saúde, na indústria. Estas inovações surgem porque 0 ser humano tem necessidade de mudança e precisa acompanhar todas as 
transformações que ocorrem na sociedade: diferentes atitudes, comportamentos, práticas e ideias. Segundo Rivas Navarro (2000), puede decirse que innovación es la incorporación de algo nuevo dentro de uma realidad existente, em cuya virtude ésta resulta modificada" (p. 20).

As inovações têm como objetivo o aperfeiçoamento de um produto ou serviço, seja na resolução de problemas, desenvolvimento de ideias ou $\mathrm{n}$ melhoria de desempenho. Uma vez assimilada a informação sobre uma inovação, "ela se incorpora ao nosso universo de conhecimentos e habilidades e fazemos uso dela na medida de nossas possibilidades e necessidades" (Kenski, 2014, p. 44).

Com o intuito de inovar e atender as necessidades dos alunos e servidores da Universidade Federal de Santa Maria, pensou-se em aprimorar o processo de edição e formatação de textos acadêmicos que devem seguir as diretrizes contidas no Manual de dissertações e teses com a oferta de um suporte tecnológico. De acordo com Silingovski (2013) os recursos tecnológicos utilizados, independente do tipo, "auxiliam como suporte didático, pedagógico e científico, que são imprescindíveis para que o ser humano alcance autonomia e independência em sua formação" (p. 15). Esses recursos são as ferramentas que possibilitam ao usuário encontrar o que desejam da melhor forma possível, atingindo um objetivo de uma inovação.

O MDT "tem como objetivo orientar e definir a forma de apresentação de trabalhos científicos da UFSM, abrangendo os elementos gráficos de organização e redação de dissertações e teses" (UFSM, 2015, p. 9). Engloba também a orientação de trabalhos de conclusão de curso de graduação e de iniciação científica. Por meio dele busca-se manter uma identidade e unificação de procedimentos de apresentação escrita de trabalhos científicos, com fundamentação na legislação nacional, na experiência das universidades brasileiras e nos parâmetros internacionais.

Sua elaboração considera as recomendações da Associação Brasileira de Normas Técnicas, sendo adaptada às áreas do conhecimento; à autonomia dos regulamentos dos cursos; à atual forma de disponibilização da produção científica por meio da Biblioteca Digital Brasileira de Teses e Dissertações e aos novos formatos de apresentação dessa produção.

A plataforma de suporte e incremento na função do MDT sugerida como inovação contribuirá de forma significativa no processo de padronização de todos os trabalhos produzidos na instituição, além de racionalizar tempo dos envolvidos, que podem empregar mais atenção na produção textual do conteúdo e não em sua formatação. Isso significa maior agilidade e eficiência, tornando o trabalho mais acessível e prático. Vai atuar também como auxiliar no processo educativo pois, embora não seja nem o objeto, nem a sua substância, nem a sua finalidade, estará presente em algum momento do processo pedagógico, neste caso a finalização de sua certificação para conclusão de curso (Kenski, 2014).

Justifica-se ainda sua implantação por ser um modelo ao alcance de todas as pessoas vinculadas com a instituição, de todos os cursos (técnicos, graduação e pósgraduação), contribuindo para a facilitação e dinamismo dessa etapa da produção científica na UFSM. 
O serviço proposto oferece um modelo pré-pronto de todos os tipos de produção científica utilizados na UFSM - teses, dissertações, TCC's, monografias -, nos formatos ".docx", ".odt" e LaTex. Desta forma, possibilita a sua utilização em sistemas operacionais Linux e Windows com softwares gratuitos e proprietários.

De acordo com Alves et al. (2005), o LaTeX consiste de uma linguagem de programação para processar textos. O nome TEX é o conjunto de 3 letras gregas: $\mathrm{\tau}$ (Tau), (Épsilon) X (Chi, pronunciado qui), pronunciando-se corretamente latéc. Nel, o autor se preocupa apenas com o conteúdo e estrutura do documento e a complexidade de formatação, tabulação e hifenização é transferida para o LaTeX. É recomendado para a criação de artigos, relatórios, livros, teses, etc., pois esses documentos possuem uma estrutura bem definida. É uma solução multiplataforma - troca de arquivos entre sistemas operacionais sem perdas - e tem vários modelos pré-definidos. $O$ autor indica a estrutura lógica do documento a partir de marcadores, que geram um resultado final, pronto para visualização e impressão.

O usuário pode se deparar com duas dificuldades: aprender LaTeX requer uma certa dedicação e prática por parte do usuário e, em geral, não é adequado para documentos que não possuam uma estrutura bem definida.

Para a utilização do modelo sugerido, o usuário acessa ao link, escolhe o programa que tem maior afinidade para trabalhar - Word, Writer ou LaTeX - e, a partir daí, completa com os dados conforme solicitado pela plataforma. Ao finalizar o preenchimento total, gera $\mathrm{o}$ arquivo completo, já formatado conforme as normas e com todo seu conteúdo. $\mathrm{A}$ figura a seguir apresenta graficamente a concepção da plataforma proposta. É possível identificar que a primeira bifurcação nos remete a utilização de modelos ditos estáticos, os templates, nos quais o usuário irá adaptar o conteúdo dos arquivos às suas necessidades. Já o caminho que nos leva à modalidade interativa da plataforma remetenos ao processo de geração de documentos mediante a inserção de informações pelo usuário. A inserção destas informações, por sua vez, pode ser feita de duas maneiras: utilizando formulário web, recomendada para desktops, ou utilizando aplicativo para smartphone, recomendada para dispositivos móveis.

Figura 1 -

Sugestão de opções para implementação.

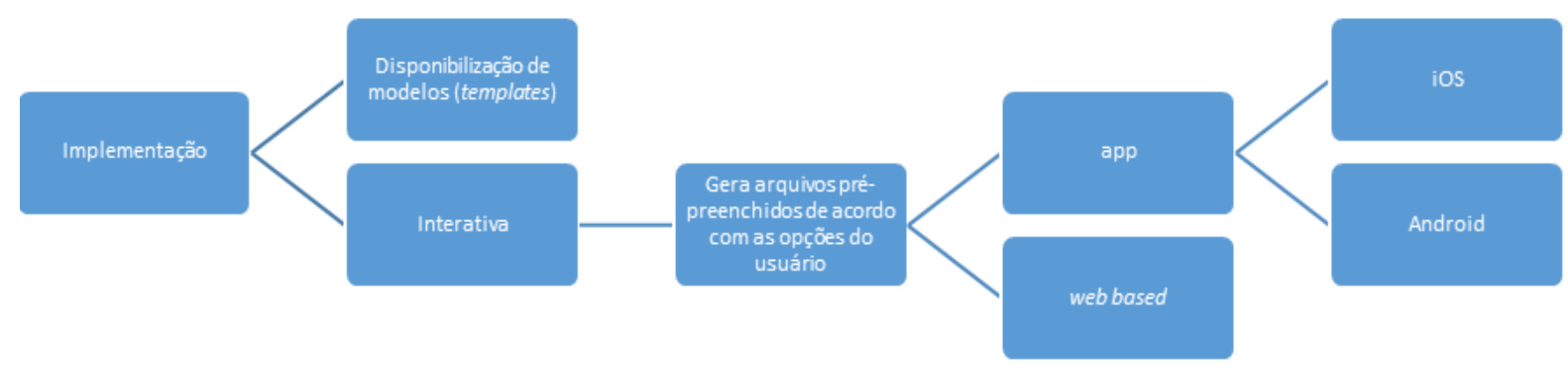


Figura 2 -

Disponibilização de modelos: arquivos-modelo formatados com comando de o quê preencher e onde preencher.

\begin{tabular}{|c|}
\hline TÍTULO \\
PROFESSOR \\
\\
CIDADE \\
MÊS E ANO \\
\hline
\end{tabular}

No modelo interativo há o preenchimento de campos pré-determinados, podendo ser executada em aplicativos: softwares desenvolvidos para serem instalados em um dispositivo eletrônico móvel, e web based, onde o design é direcionado para navegadores de internet como Firefox ou Chrome, executados em desktops ou notebooks.

Exemplo: os dados a serem preenchidos são solicitados em campos específicos determinados, onde em cada um é inserido o conteúdo. Os campos a preencher fazem parte do trabalho, como título, data, cidade, modalidade - tese, dissertação, TCC ou monografia -, orientador, co-orientador, palavras-chave, resumo, lista de capítulos, introdução, etc.

Figura 3 -

Modelo interativo.

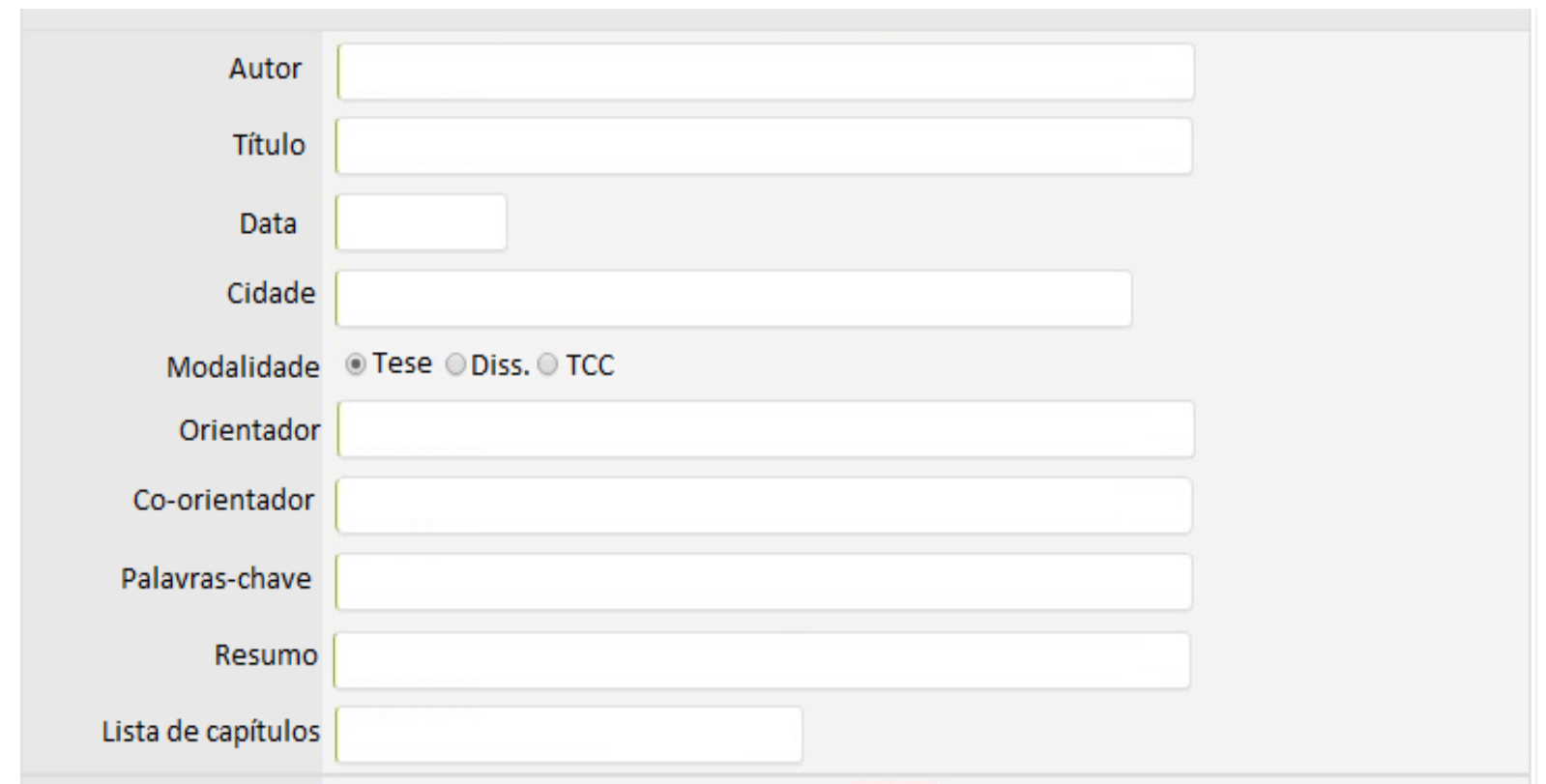


Trata-se uma inovação em que os gestores podem avaliar sua implantação na UFSM, pois além da possibilidade de minimizar problemas de padronização, auxilia e beneficia o trabalho dos usuários, otimiza as funções da equipe, sendo que os bibliotecários que atendem nesses esclarecimentos, podem atender novas demandas.

Sua viabilidade vai depender da criação de um grupo de trabalho com bibliotecários, programadores, engenheiros de computação, programadores visuais, etc. Depois da formatação inicial não exigirá maiores reforços e necessidade de acompanhamento. A sua atualização estará muito ligada à correção de eventuais bugs e às adaptações que podem ocorrer a cada atualização necessária da MDT.

\section{Mapas mentais: uma ferramenta de apoio a aprendizagem}

Ana Paula de Almeida

Os mapas mentais constituem-se numa ferramenta em formato de diagrama que permite melhorar o desempenho nos estudos de forma mais clara e eficiente, possibilitando ampliar os resultados sobre o processo educativo.

No Instituto Federal do Rio Grande do Sul, campus Ibirubá, percebe-se, cotidianamente, que os estudantes enfrentam várias dificuldades de como organizar e planejar seus estudos. Na modalidade de ensino integral, os estudantes passam muito tempo na escola, possuindo um número elevado de disciplinas, além de pouco tempo para estudar, muitos acabam desestimulando-se com falta de interesse pela escola e pelo curso.

A partir dessa percepção, procurou-se criar uma atividade configurada a partir da seguinte pergunta: Como estudar melhor? A proposta teve como finalidade a utilização dos mapas mentais como um recurso de intervenção a partir da percepção de aprendizagem dos estudantes, da possibilidade de estudar e assimilar os conteúdos de modo mais eficiente, clara e objetiva.

Figura 4 -

Modelo de mapa mental.

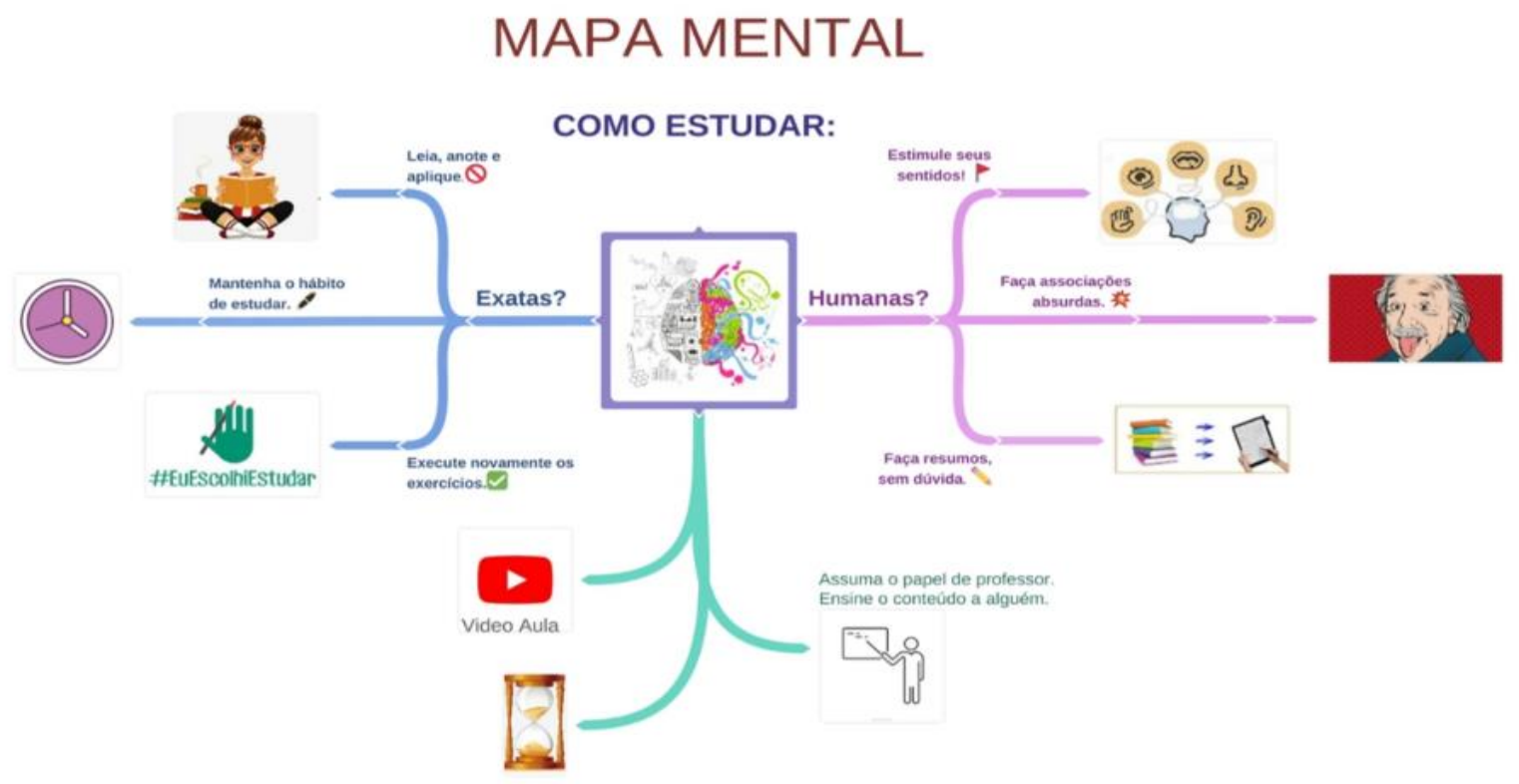


Segundo Tony e Barry Buzan (1996) o cérebro é uma parafernália de criatividade e tudo que ele precisa são ferramentas corretas. Por isso, os mapas mentais correspondem a um método não-linear de aprendizagem, que tem como princípio o modo de organização cerebral, no qual constituem-se em conexões em que a retenção dos conteúdos aumenta muito mais por meio de imagens, linhas, curvas e poucas palavras.

Nesse sentido, o mapa mental consiste na representação de pensamentos que se irradiam a partir de uma temática central. Trata-se de um método visual em formato de diagrama que impulsiona o brainstorming, ampliando os conceitos e possuindo uma imagem mais inovadora. $O$ formato dos mapas mentais é muito variado, podendo ser bem elaborados a mão ou no computador, por meio de plataforma livre, pode-se incluir imagens e diversas cores. Podendo ser usado para os mais diversos contextos e fins (Buzan; Buzan, 1996).

O mapa é criado a partir de um tema central irradiador, podendo ser uma palavrachave ou uma figura. Após isso se adiciona as ramificações que levam os conteúdos dispostos em tópicos e subtópicos que compõe o assunto a nível macro. Desta forma, para comprovar a eficácia da aplicação dos mapas mentais em projetos ativos de apoio a aprendizagem, foi desenvolvida uma experiência de intervenção com a turma do $1^{\circ}$ ano do curso técnico em Informática do IFRS, campus Ibirubá. A turma possui 32 estudantes matriculado e foi organiza em oito grupos.

Para realizar essa atividade foi necessário apresentar a proposta dos mapas mentais, conceito e aplicação, tendo como tema central: Como estudar de forma melhor? Nessa tarefa os grupos de estudantes deveriam utilizar o material didático disponibilizado, aplicar os conceitos e sistematizar as informações. O produto final era produção de um mapa mental aplicando todos os recursos do mapa.

Com vistas a gerar um maior impacto na comunidade escolar, cada grupo organizou a disponibilização do material através de vários espaços do campus, nos corredores, na biblioteca, no acesso ao refeitório e na parada de ônibus.

Figura 5 -

Algumas atividades apresentadas.
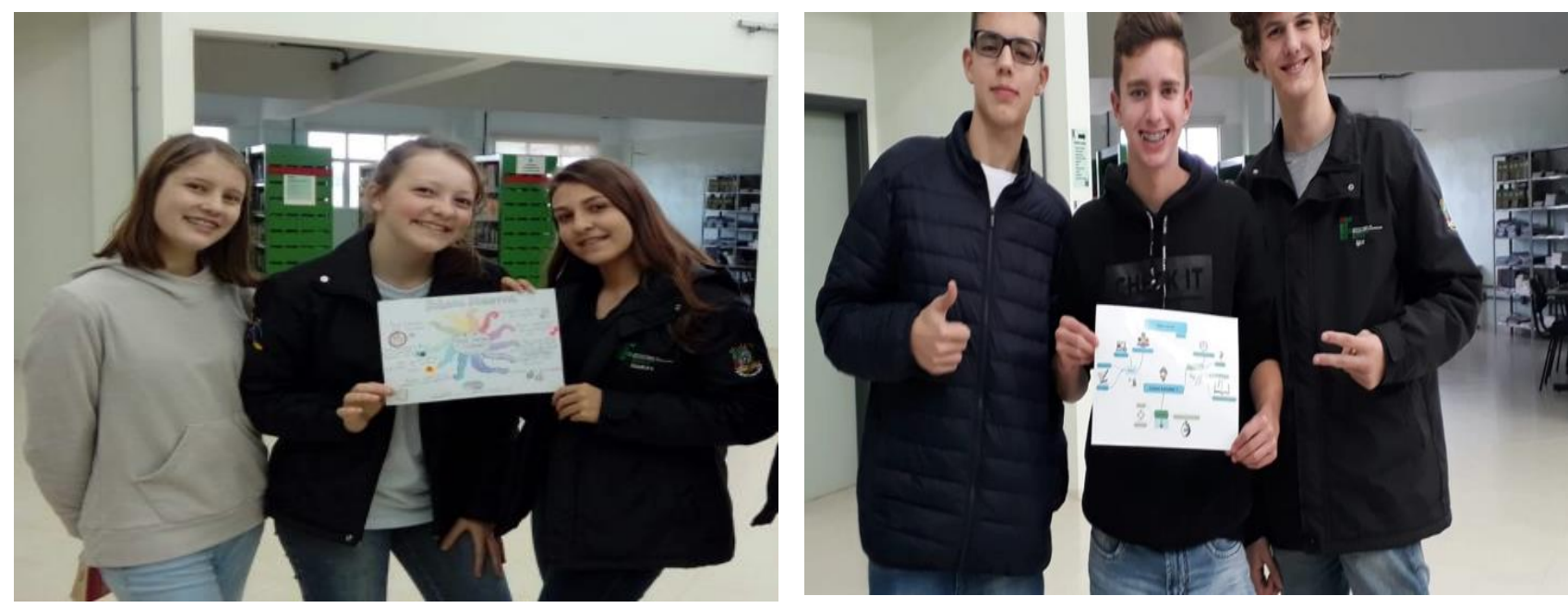

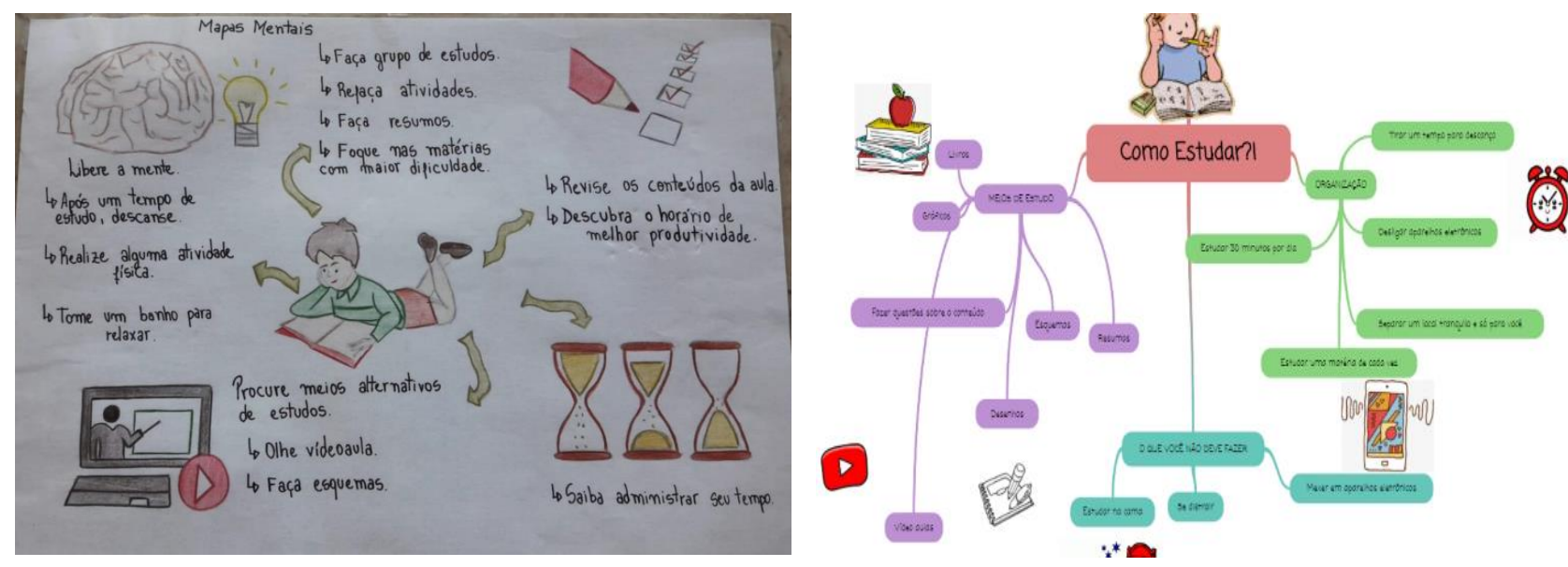

Os mapas mentais possibilitaram unir várias qualidades importantes como: criatividade, colaboração, interação, objetividade e hierarquia de conhecimentos, fundamentando ordenadamente os saberes. Outro atributo importante foi a capacidade de clareza e objetividade no desenvolvimento do raciocínio, diminuindo a quantidade de informações que devem ser apreendidas, o que torna os mapas mentais um método com uma qualidade importantíssima para a era da informação abundante selecionando apenas conteúdos efetivamente relevantes.

Esta proposta fundamenta-se, também, no conceito de inovação de Navarro (2014), pois justifica-se pela possibilidade de melhorar o desempenho ou resultado do estudante, com mais e melhor aprendizagem, envolvendo a ação de inovar.

Com a experiência de intervenção foi possível observar que os estudantes conseguiram relacionar eficácia e objetividade, criatividade e hierarquia dos conceitos. Além das possibilidades de explorar os recursos visuais e lingüísticos, Desta forma, os mapas mentais apresentam-se em uma ferramenta inovadora, repercutindo significativamente no contexto escolar.

\section{Full-Time Trajectory - FTT: ferramenta auxiliar de gestão educacional para acompanhar a trajetória formativa do estudante na contemporaneidade} Marcos José Andrighetto

Já há algum tempo, com o surgimento de uma vasta quantidade de aparatos eletrônicos criados para facilitar as tarefas do dia-a-dia, as tecnologias passam a ser uma realidade no cotidiano da grande maioria da população mundial. Neste universo os aparelhos eletrônicos conhecidos como gedgets estão cada vez mais presentes em todas as residências. Um dos mais comuns é o celular do tipo smartphone, que além de funcionar como aparelho telefônico para realizar e receber chamadas, também, é utilizado como uma espécie de minicomputador portátil para acesso à internet e outros aplicativos.

No Brasil, segundo dados do IBGE (relatório PNAD, 2016), 97,2\% dos domicílios brasileiros utilizam o celular para acesso à internet. Frente a esse cenário virtualizado em que o acesso à informação é amplo e gratuito, possibilitando a aprendizagem em ambientes não escolares, está à necessidade de adaptação das escolas, proporcionando a utilização destas tecnologias para fins educacionais. 
Nesse sentido, buscou-se apresentar uma ferramenta auxiliar de gestão escolar por aplicativo de celular que se justifica por no mínimo dois aspectos: pelo elevado alcance que ferramentas dessa natureza possibilitam e pela importância de acompanhar a trajetória formativa dos estudantes em tempo real, identificando as dificuldades de aprendizagem por eles enfrentadas.

Dessa forma, o FTT inova ao possibilitar o acompanhamento da trajetória formativa dos estudantes em tempo real, interligando setores e fornecendo aos pais um panorama do processo de aprendizagem. Esse conjunto de vantagens possibilita a atuação rápida, eficaz e pontual dos envolvidos nos processos de ensino e aprendizagem, potencializando a atuação do gestor e fornecendo elementos que consolidam e dão visibilidade à instituição de ensino. Com o uso de um smartphone este aplicativo pode ser acessado pelos professores, coordenadores de cursos, assistência estudantil e pais, interligando os diversos sujeitos envolvidos na construção do conhecimento e garantindo o acompanhamento sólido da trajetória formativa dos estudantes.

Em linhas gerais, o FTT funciona como uma espécie de banco de dados da trajetória formativa de todos os alunos de uma instituição de ensino, cujos dados serão armazenados na nuvem e organizados em planilhas individuais identificadas com foto e nome do aluno, instituição de ensino, curso, turma e data de ingresso. É importante dizer que essa configuração inicial é básica e poderá ser editada de acordo com os interesses e especificidades que a instituição escolar julgar necessária, podendo incluir ou excluir campos, uma vez que todos são plenamente editáveis. No FTT o cadastro dos alunos poderá se realizar de duas maneiras: extraindo os dados do sistema já existente na instituição de ensino, nesse caso, basta apenas exportá-los para a nuvem, inserindo manualmente os dados cadastrais dos educandos, recurso este, que permite também, a migração entre cursos da instituição.

A dinâmica de funcionamento do FTT consiste em destinar, para cada estudante cadastrado, uma planilha para os registros da sua trajetória formativa, com cinco campos distintos: data, professor, disciplina, relato, encaminhamento. Essas planilhas são de acesso e edição em tempo real e compartilham as informações com setores estratégicos da instituição de ensino, tais como: direção geral, direção de ensino, coordenação de curso, assistência estudantil e os pais dos alunos. No entanto, vale dizer que o acesso aos dados construídos obedece às políticas de privacidade vigentes e são de acesso restrito, ou seja, o gestor da instituição ou a quem ele designar terá no FTT, o perfil de administrador, o que lhes dará acesso total às planilhas. Esse administrador, por sua vez, incluirá os demais acessos, como os professores que atuam no curso, a assistência estudantil e os pais, dando-Ihes acesso apenas aos campos que a instituição entender necessários. Assim, nem todos os perfis terão acesso total as tudo, quem define essas prerrogativas é o administrador, conferindo assim, total autonomia à gestão da unidade educacional. $\mathrm{Na}$ figura a seguir apresenta-se a sugestão de interface do app, no módulo administrador. 
Figura 6 -

Interface do app inicial/acesso/edição.

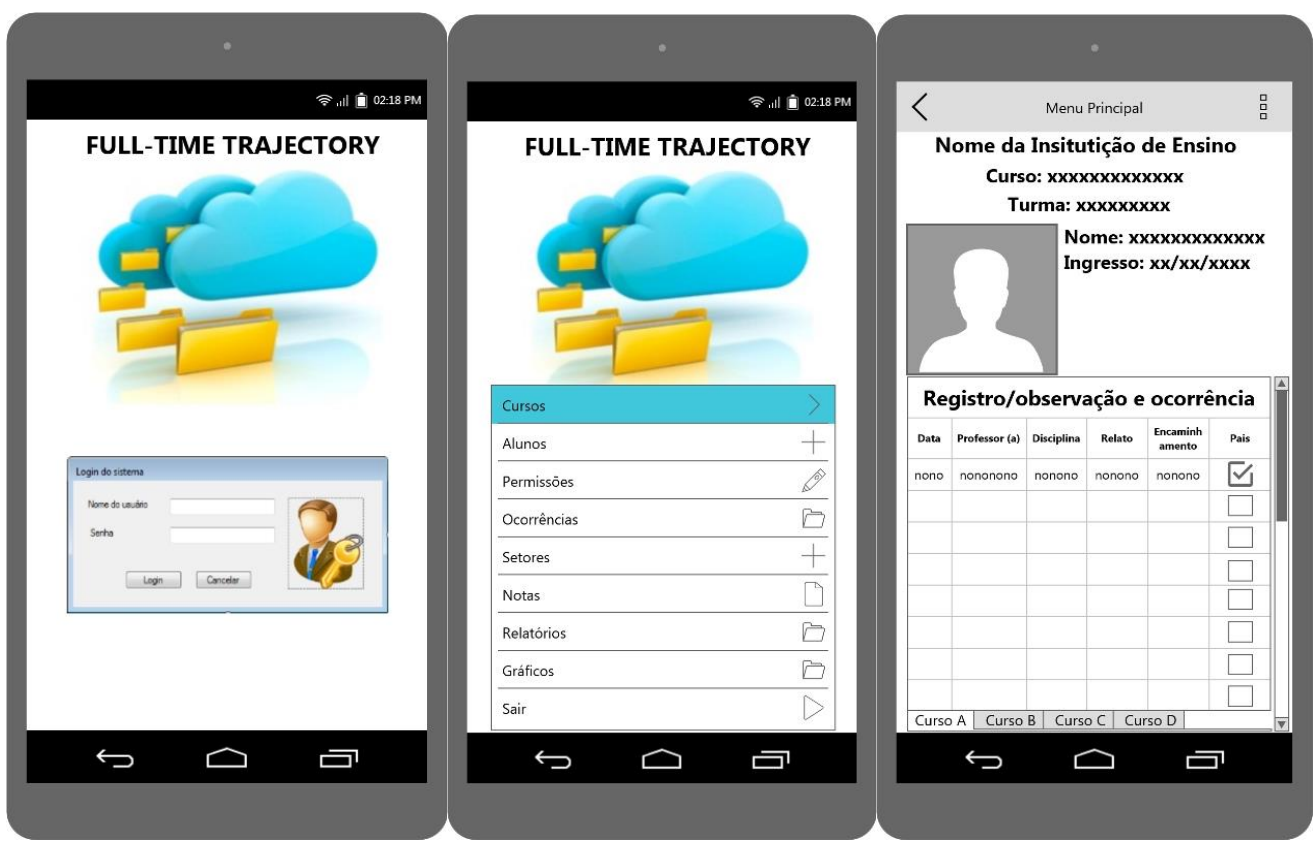

Outra facilidade que o FTT oferece é a geração de relatórios e gráficos do desempenho dos alunos. Isso permite acompanhar a evolução da aprendizagem e identificar os pontos fortes e fracos dos educandos. Dessa maneira, é possível reforçar estudos em determinadas disciplinas ou potencializar o desenvolvimento dos pontos fortes, fazendo com que esses alunos se tornem diferenciados dos demais e aumentem, significativamente, suas possibilidades de alcançar sucesso e se inserir no mundo do trabalho. Aos pais, também poderá ser dado o acesso aos registros da trajetória formativa dos filhos. Mas, nesse caso, como algumas informações poderão ser de interesse somente da instituição ou ainda, por questões legais e éticas não podem ser socializadas, o gestor poderá escolher quais campos os pais terão acesso. Para isso, de forma rápida e fácil, bastará apenas selecionar os registros que serão disponibilizados aos pais. $\mathrm{Na}$ figura 7 é possível visualizar a sugestão de interface disponibilizada aos pais ou responsáveis. 
Figura 7 -

Interface do app pais/responsáveis.

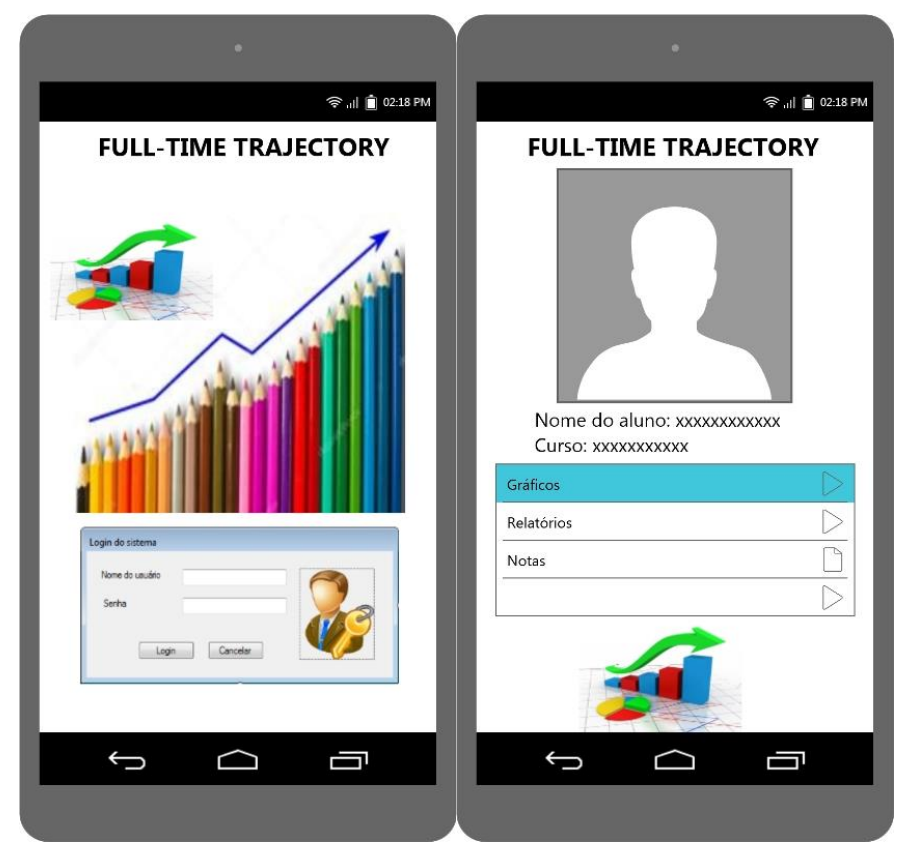

Pela gama de possibilidades inovadoras que o aplicativo FTT oferece, pode ser facilmente utilizado para escolas da rede pública como por escolas privadas, que desejarem se destacar no mercado, importante diferencial entremeio ao leque de instituições de ensino disponível no Brasil.

\section{Ferramenta de ensino e aprendizagem interativa Tiago Saidelles}

Os professores atentos às mudanças podem escolher fundamentalmente dois caminhos, um mais ameno e outro mais amplo. No caminho mais ameno eles mantêm o modelo curricular predominante, mas priorizam o envolvimento maior do aluno, com metodologias diferenciadas como o ensino por projetos de forma mais interdisciplinar. Outros propõem modelos mais inovadores, disruptivos, que redesenham o projeto, os espaços físicos, as metodologias baseadas em atividades, desafios, problemas, jogos nas quais cada aluno aprende no seu próprio ritmo e necessidade, podendo também aprender com os outros por meio de grupos e projetos, com supervisão dos professores orientadores.

Tendo em vista a dificuldade dos professores em encontrar ferramentas que possibilitem a conexão das tecnologias com as metodologias de ensino e aprendizado, pensamos que seria interessante ter uma ferramenta que proporcionasse ao professor a possibilidade de disponibilizar seus materiais didáticos de maneira eficiente.

Também foi levado em consideração para o desenvolvimento da ferramenta os conceitos abordados pelas metodologias ativas, em que o professor não fica na frente da sala como o detentor do conhecimento, os alunos como meros ouvintes. Com o uso deste recurso os alunos terão possibilidade de aprender no seu tempo. Com a implementação 
desta ferramenta o mesmo irá aprimorar a qualidade da educação, proporcionando novos caminhos para o ensino e aprendizagem, além de novas metodologias, formando educadores e os ajudando a descobrir estratégias inovadoras para o aperfeiçoamento do processo educacional, podendo também, tornar as aulas mais atraentes ampliando possibilidades para alunos e para professores.

O Sistema Ensino e Aprendizagem consiste em uma plataforma web, desenvolvida em linguagem de programação PHP e com uma base de dados MySql. Por meio dele o aluno irá acessar a página inicial onde terá que realizar um cadastro para aquisição de um usuário e senha, que será utilizado para sua autenticação no sistema. Após o login o usuário terá seu redirecionado para o menu inicial, onde o mesmo selecionará o ano e posteriormente a disciplina a ser revisada naquele determinado momento. Após a realização destas etapas o estudante poderá escolher qual matéria, daquela determinada disciplina irá revisar. O conteúdo será disponibilizado por meio de um display de tutoriais pelos quais terá a chance de navegar pelas lições pelos botões de avançar e retroceder. A plataforma possibilitará ao usuário realizar anotações e soluções de exercício em um editor de texto personalizado, onde estará disponível opções como imprimir, salvar, montar formulários, tabelas, propiciando ao estudante ter um controle de suas atividades realizadas. Após o término da lição a mesma poderá ser enviada para o professor pelo email.

O sistema tem por objetivo disseminar o modelo de Ensino Híbrido, para que desta forma o mesmo possa contribuir na educação, estimulando os professores a utilizar novas metodologias de ensino e proporcionar o uso dos recursos contidos na ferramenta. Pode ser, ainda, um complemento nas suas práticas pedagógicas, mesclando os dois modos de ensino - o online, em que geralmente o alunos estudam fora do ambiente escolar, em diferentes horas e locais, que podem inclusive guardar dados individuais sobre características gerais do seu momento de estudo, acertos, erros, correção automática, tempo total de estudo, conteúdo estudado, e o off-line, momento em que o aluno estuda em grupo, com o professor ou colegas, valorizando a interação e o aprendizado coletivo e colaborativo, desta forma a ferramenta irá ajudar para o crescimento da educação e para disseminação do conhecimento.

\section{Considerações finais}

As proposições expostas no decorrer do texto nos mostram que é possível desenvolver ferramentas de ensino e aprendizagem que auxiliem a gestão escolar. Pelas quatro propostas apresentadas nota-se que, com a utilização de mapas mentais, pode se potencializar a aprendizagem, tornando-a dinâmica e atrativa. No que se refere à plataforma de apoio para formatação de textos acadêmicos sua implantação poderá ser relevante, pois, orienta os estudantes e padroniza os trabalhos finais que irão compor 0 acervo da universidade. Por meio do app que interliga setores da instituição de ensino e acompanha em tempo real a trajetória formativa dos estudantes, o aplicativo FTT poderá dar celeridade e eficácia às correções dos desvios e dificuldades formativas. Por fim, adotar a gamificação como processo de ensino e aprendizagem visa à tornar atrativo o desenvolvimento das disciplinas, uma vez que a interação entre o estudante e o game, que virtualiza o ambiente escolar em uma espécie de jogo educativo, aproxima a sala de aula da realidade a qual se encontram imersos atualmente. 
A partir deste trabalho nos deparamos com a importância de analisar novas metodologias de ensino e aprendizagem para que possamos conectar as tecnologias no contexto educacional. Portanto, para se ter êxito nesse sentido é necessário fazer uso de novas práticas pedagógicas, tornando as aulas mais engajadoras e estimulantes para os estudantes no seu processo de ensino e aprendizado. Em tempos em que se procura a inovação, a geração de novas idéias de produtos ou serviços, como os apresentados aqui, pode resultar em vantagens e diferenciação nos lugares em que são utilizados.

\section{Referências}

ALVES, Débora Pandolfi; SANCHEZ, Ricardo Nabinger; DAMASIO, Felipe W. Minicurso de LaTeX. São Leopoldo: Unisinos, 2005. Disponível em: <http://rnsanchez.wait4.org/pdf/Unilnfo2004_slides.pdf>. Acesso em 26 maio 2018.

BUZAN, Toni; Buzan, Barry. The mind map book: how to use radiant thinking to maximize your brain's untapped potential. New York: Plume, 1996.

IBGE. Pesquisa nacional por amostra de domicílios contínua. Disponível em $<$ https://biblioteca.ibge.gov.br/visualizacao/livros/liv101543.pdf>. Acesso em 30 jun. 2018.

KENSKI, Vani. Moreira. Educação e tecnologias: o novo ritmo da informação. São Paulo: Papirus, 2014.

MESSINA, Graciela. Mudança e inovação educacional: notas para reflexão. Cadernos de Pesquisa, São Paulo, n. 114, 2001, p. 225-233.

NAVARRO, Manuel Rivas. Innovacion educativa: teoria, procesos y estratégias. Madrid: Síntesis, 2000.

SILINGOVSCHI, Regina Rita Liberati. A função pedagógica da biblioteca universitária enquanto organização e espaço educacional: estudo de caso. 2013. 162f. Dissertação (mestrado em Ciências Humanas). Universidade do Oeste Paulista, Presidente Prudente, $2013 . \quad$ Disponível em http://bdtd.unoeste.br:8080/tede/bitstream/tede/889/1/DISSERTACAO\%20Regina\%20DE FESA\%203DEZ2013.pdf. Acesso em 13 jan. 2018.

TAKAHASHI, Tadão (org.). Sociedade da informação: livro verde. Brasília: Ministério da Ciência e Tecnologia, 2000.

Adriane Terezinha Filipetto é graduada em Farmácia e Bioquímica, especialista em Gestão de Recursos Humanos. É técnico-administrativo na Universidade Federal de Santa Maria e estudante do curso de mestrado em Educação Profissional e Tecnológica do Colégio Técnico Industrial de Santa Maria.

Orcid: https://orcid.org/0000-0001-8090-0030.

Endereço: Rua Dirceu Castilhos Teixeira, 59 - 97105-080 - Santa Maria - RS.

E-mail: atfilipetto@yahoo.com. 
Ana Paula de Almeida é bacharel em Serviço Social, com especialização em Educação Ambiental e Elaboração e Gestão de Projetos Sociais. Assistente Social no Instituto Federal de Educação, Ciência e Tecnologia do Rio Grande do Sul, campus de Ibirubá.

Orcid: https://orcid.org/0000-0001-7619-1737.

Endereço: Rua Reinoldo Braatz, 807 - 98200-000 - Ibirubá - RS - Brasil.

E-mail: ana.almeida@ibiruba.ifrs.edu.br.

Marcos José Andrighetto é graduado em Gestão Pública e estudante do curso de mestrado em Educação Profissional e Tecnológica do Colégio Técnico Industrial de Santa Maria. É técnico-administrativo em educação no Instituto Federal de Educação, Ciência e Tecnologia Farroupilha, campus de Santo Augusto.

Orcid: https://orcid.org/0000-0002-9672-4980.

Endereço: Rua Salgado Filho, 411 - 98590-000 - Santo Augusto - RS - Brasil.

E-mail: marcos.andrighetto@iffarroupilha.edu.br.

Tiago Saidelles é graduado em Tecnologia em Redes de Computadores pela UFSM e estudante no curso de mestrado em Educação Profissional e Tecnológica do Colégio Técnico Industrial de Santa Maria.

Orcid: https://orcid.org/0000-0002-5885-2965.

Endereço: Rua Antônio Porto Alegre, 5 - 970035-080 - Santa Maria - RS - Brasil.

E-mail: tiago-saidelles@redes.ufsm.br.

Claudemir de Quadros é licenciado em História, com mestrado e doutorado em Educação. É professor na Universidade Federal de Santa Maria/RS e atua em cursos de formação de professores e no Programa de Pós-Graduação em Educação Profissional e Tecnológica.

Orcid: http://orcid.org/0000-0002-1204-0355.

Endereço: Rua Gabriel Bolzan, 30 - 97095-500 - Santa Maria - RS - Brasil.

E-mail: claudemirdequadros@gmail.com.

Recebido em 3 de outubro de 2018.

Aceito em 14 de dezembro de 2018.

(c) (i) 